\title{
Evaluation of Economics Journals Based on Reduction Algorithm of Rough Set and Grey Correlation
}

\author{
Mei-Jia Huang ${ }^{1}$, Yuan-Biao Zhang ${ }^{2,3}$, Jie-Huan Luo ${ }^{1} \& \mathrm{He} \mathrm{Nie}^{1}$ \\ ${ }^{1}$ Electrical and Information School, Jinan University, Zhuhai 519070, China \\ ${ }^{2}$ Packaging Engineering Institute, Jinan University, Zhuhai 519070, China \\ ${ }^{3}$ Key Laboratory of Product Packaging and Logistics of Guangdong Higher Education Institutes, Jinan University, \\ Zhuhai 519070, China \\ Correspondence to: Yuan-Biao Zhang, Packaging Engineering Institute, Jinan University, Zhuhai 519070, China. \\ E-mail: zybt@jnu.edu.cn
}

Received: December 19, 2014

Accepted: January 25, 2015 Online Published: February 20, 2015

doi:10.5539/jms.v5n1p140

URL: http://dx.doi.org/10.5539/jms.v5n1p140

\begin{abstract}
In order to evaluate economics journals objectively and avoid the problem arising from artificial subjective factors, this paper put forward an evaluation of economics journals model based on reduction algorithm of rough set and grey correlation. Firstly, it used reduction algorithm of rough set based on equivalence relation to determine the key indicators. Secondly, it determined the key indicators weights by using grey correlation degree method, then used dominance relation of rough set method to determine another group of weights of key indicators. Lastly, it combined TOPSIS with two groups of weights above to evaluate and rank economics journals and compared the results, proved the evaluation model of economics journals based on reduction algorithm of rough set and grey correlation could be applied in evaluation of economics journals with high practicality and reasonability.
\end{abstract}

Keywords: evaluation of economics journals, rough set, grey correlation, dominance-based rough set, TOPSIS

\section{Introduction}

The journal industry has made great progress in our country. The quality of journals becomes more important as they are increasing in the number. Therefore, it is of great significance to establish reasonable and objective indicator evaluation systems to evaluate journals level objectively. Many scholars have used different evaluation indicators and methods to set up kinds of journal evaluation systems and improved these systems as well. Zhang Hong et al. (2008) use the principal component analysis method to evaluate scientific journals. Li et al. (2007) put forward a comprehensive evaluation method based on variance right to determine the indicators weights and drew a conclusion that key indicators can replace all indicators to evaluate journals. Liu et al. (2006) analyse the relationship between academic indicators using normalization and conventional evaluation results for sci-tech journals. Wang et al. (2012) use key ratio method to determine key indicators in the evaluation of journals and used TOPSIS method to evaluate and rank journals.

Rough set theory is a math tool for dealing with imprecise, inconsistent and incomplete information and knowledge in quantitative analysis (Pawlak, 1982). Rough set theory is commonly used in data classification. Its basic idea is to utilize equivalence relation classes through attribution reduction and decision rule reduction, to achieve knowledge mining and reduction in the case of keeping the same ability for classification. Xiao et al. (2001) use rough set theory to analyse the evaluation result of research project supported by science foundation. Xiong Ping et al. (2003) put forward a new subjective weighting method based on rough sets. Rough set theory has been developed rapidly. It has a high application value in multiple attribute decision making and can be used in the academic evaluation system.

Grey correlation analysis is an important branch of the grey system theory (Deng, 2002). The basic idea of grey correlation analysis is to judge whether the contact is close according to the similar degree of sequence curve geometry shape. The more similar tow curves are, the greater the correlation between corresponding sequences are, and vice versa. So it can identify the influence degree of the object to be identified to the object of study by comparing the degree of the correlation. Compared to the system analysis methods such as principal component analysis and regression analysis, grey correlation analysis is independent of the sample capacity and the rules of 
probability distribution and its computation cost is small.

On the basis of the researches of others, this paper puts forward an evaluation of economics journals model based on reduction algorithm of Rough Set and Grey Correlation. Firstly, using reduction algorithm of Rough Set to determine the key indicators, then determine the key indicators weights by using grey incidence degree analysis method, and then using dominance relation of rough set method to determine another group of weights of these key indicators (Lv et al., 2012). Lastly, we combines TOPSIS with two groups of weights determined above to evaluate and rank economics journals and compare the results (Qian et al., 2008), proves the evaluation model of economics journals based on reduction algorithm of rough set and grey correlation is more reasonable.

\section{The Reduction Evaluation Model Based on Grey-Rough Set}

This paper uses indicators reduction algorithm based on the equivalence relation of rough set theory to reduce seven common evaluation indicators of journals to get the key indicators. Then through studying the correlation of feature data of evaluation indicator and feature data of journals ranks to obtain the importance of each factor, and weight according to their importance. We combine the weight with TOPSIS method for comprehensive evaluation of journals. And compare results with another weighting method — dominance relation of rough set.

\subsection{Rough Set Reduction}

There are some definitions on rough set reduction as follows (Zhou, 2008):

Definition 1: Let $N$ denotes a family of equivalence relations, if $\operatorname{IND}(N)=\operatorname{IND}(R-\{N\})$, we call $N$ can be reduced in the equivalence relation family $R$, otherwise cannot. If any equivalence relation $N$ of $R$ cannot be reduced, we called $R$ is independent, otherwise known as dependent.

Definition 2: Set $R=\left(r_{i j}\right)_{m \times n}$, if $M$ is independent, and $I N D(M)=I N D(S)$, then $M$ is a reduction of equivalence relation family $\mathrm{S}$.

Base on Rough set theory and reduction principles, we can obtain reduction algorithm of evaluation indicators, described as follows:

Step 1: for the evaluation indicators system $R=\left\{n_{i}\right\}(i=1, \ldots, k)$, obtaining $\operatorname{IND}(R)$.

Step 2: for $i=1, \ldots, m$, obtaining $I N D\left(R-\left\{n_{i}\right\}\right)(i=1, \ldots, k)$.

Step 3: if $I N D\left(R-\left\{n_{i}\right\}\right)=I N D(R)$, that is, $n_{i}$ is miscellaneous indicators of indicator system $R$ can be removed, if not, $n_{i}$ is necessary indicators cannot be removed.

\subsection{Grey Correlation Weights}

The evaluation weight determination of comprehensive evaluation system is an important factor to affect the results of the evaluation, thus determining the evaluation weight objectively and reasonably is particularly important. Common methods of endow with weight are subjective weighting method, objective weighting method and a combination of subjective and objective weighting method. In this paper, we do a gray correlation weights analysis, through studying the correlation of feature data of evaluation indicator and feature data of journals ranks to obtain the importance of each factor, and weight according to their importance.

Some definitions about grey correlation as follows:

A system for behavior sequence:

$$
\left\{\begin{array}{c}
X_{0}=\left(x_{0}(1), x_{0}(2), \cdots, x_{0}(n)\right) \\
X_{1}=\left(x_{1}(1), x_{1}(2), \cdots, x_{1}(n)\right) \\
\cdots \\
X_{i}=\left(x_{i}(1), x_{i}(2), \cdots, x_{i}(n)\right) \\
\cdots \\
X_{m}=\left(x_{m}(1), x_{m}(2), \cdots, x_{m}(n)\right)
\end{array}\right.
$$

The correlation coefficient between $X_{i}$ and $X_{0}$ is:

$$
r_{i j}=\frac{\min _{i} \min _{j}\left|x_{0}(j)-x_{i}(j)\right|+\rho \max _{i} \max _{j}\left|x_{0}(j)-x_{i}(j)\right|}{\left|x_{0}(j)-x_{i}(j)\right|+\rho \max _{i} \max _{j}\left|x_{0}(j)-x_{i}(j)\right|}
$$

Get the correlation coefficient matrix:

$$
R=\left(r_{i j}\right)_{m \times n}
$$


The degree of correlation between $X_{i}$ and $X_{0}$ is:

$$
r_{i}=\frac{1}{n} \sum_{i=1}^{n} r_{i j}
$$

Where, $\rho \in(0,1)$ is resolution ratio, generally $\rho=0.5$ according to the principle of minimum information.

The calculation steps about determination of weight using grey correlation as follows:

Step 1: $X_{0}$ and $X_{i}$ do the initial treatment,

$$
X_{i}^{\prime}=X_{i} / X_{i}(1)=\left(x_{i}^{\prime}(1), x_{i}^{\prime}(2), \cdots, x_{i}^{\prime}(n)\right), i=0,1,2, \cdots, m
$$

Step 2: strives for the sequence of difference:

$$
\Delta_{i}(j)=\left|x_{0}^{\prime}(j)-x_{i}^{\prime}(j)\right|
$$

Where, $i=1,2, \cdots, m, j=1,2, \cdots, n$.

Step 3: strives for the correlation coefficient:

$$
M=\max _{i} \max _{j} \Delta_{i}(j), m=\min _{i} \min _{j} \Delta_{i}(j)
$$

Therefore, correlation coefficient is:

$$
r_{i j}=\frac{m+\rho M}{\Delta_{i}(j)+\rho M}, \rho \in(0,1), i=1,2, \cdots, m, j=1,2, \cdots, n
$$

Step 4: calculate correlation degree and weight,

$$
r_{i}=\frac{1}{n} \sum_{i=1}^{n} r_{i j}
$$

Finally, we normalize $\gamma_{0 i}$, and order

$$
\omega_{i}=\frac{r_{i}}{\sum_{i=1}^{m} r_{i}}, i=1,2, \cdots, m
$$

Where, denote $\omega_{i}$ as indicators weight.

Base on reduction of rough to get core indicators, we use grey correlation weights methods to calculate the correlation degree of journals and calculate the weight of core indicators.

\section{Instance Analysis}

This paper selects a part of journals and the data of seven common evaluation indicators of these journals from CHINESE S\&T JOURNAL REPORTS (Expanded Edition), as well as search the ranks of relevant journals in $A$ Report on Chinese Academic Journals Evaluation. Then using indicators reduction algorithm based on the equivalence relation of rough set theory to reduce seven common evaluation indicators of journals to get the key indicators. And do a determination on the indicators weights by using grey incidence degree analysis method and dominance relation of rough set method. Lastly, it combines two groups of weights above with TOPSIS method for comprehensive evaluation of journals and compares the results.

\subsection{Evaluation Indicators Reduction Based on Equivalence Relation of Rough Set}

This paper selects 20 economics journals in four grades from A Report on Chinese Academic Journals Evaluation as research objects, as well as search the data of seven common evaluation indicators of these journals from CHINESE S\&T JOURNAL REPORTS (Expanded Edition).

Let $a_{1}, a_{2}, a_{3}, a_{4}, a_{5}, a_{6}, a_{7}$ denote total citation, impact factor, current-year index, cited rate, $\mathrm{H}$ index, average amount of citations and ratio of funded papers.

The journals selected are divided into 4 grades according their ranks in A Report on Chinese Academic Journals Evaluation. Let $d$ denote grade. The range of values for $d$ is 1 to 4 , the higher the rank, the higher the value. The 
data of evaluation indicators of the journals selected shown in Table 1. We abbreviate a part of journals names because of space limitations.

Table 1. The data of evaluation indicators of 20 journals selected

\begin{tabular}{lllllllll}
\hline Journal Name & $a_{1}$ & $a_{2}$ & $a_{3}$ & $a_{4}$ & $a_{5}$ & $a_{6}$ & $a_{7}$ & $\mathrm{~d}$ \\
\hline Econ Theory and Business Management & 1739 & 1.717 & 0.324 & 0.99 & 9 & 19.39 & 0.75 & 4 \\
Studies of International Finance & 1869 & 2.08 & 0.338 & 0.96 & 10 & 15.36 & 0.475 & 4 \\
China Rural Survey & 1422 & 2.248 & 0.31 & 0.97 & 10 & 18.81 & 0.845 & 4 \\
J of Business Economics & 1365 & 1.099 & 0.171 & 0.97 & 8 & 24.52 & 0.868 & 4 \\
Economist & 1849 & 1.896 & 0.319 & 0.99 & 12 & 13.42 & 0.694 & 4 \\
J of Shanghai Lixin Univ of Commerce & 323 & 0.793 & 0.156 & 0.99 & 4 & 20.98 & 0.938 & 3 \\
Technology Economics & 1449 & 0.815 & 0.243 & 0.85 & 6 & 19.6 & 0.69 & 3 \\
On Economic Problems & 1963 & 0.782 & 0.176 & 0.97 & 7 & 7.03 & 0.49 & 3 \\
Rural Economy & 2461 & 0.997 & 0.136 & 0.97 & 7 & 6.75 & 0.703 & 3 \\
South China J of Economics & 1029 & 1.745 & 0.128 & 0.88 & 9 & 31.9 & 0.807 & 3 \\
Market Modernization & 9330 & 0.293 & 0.049 & 0.98 & 8 & 3.19 & 0.093 & 2 \\
Economic Issues in China & 369 & 0.922 & 0.153 & 0.93 & 5 & 15.43 & 0.653 & 2 \\
J of Hebei Univ of Econ and Trade & 477 & 0.808 & 0.211 & 0.95 & 4 & 8.85 & 0.325 & 2 \\
Review of Economic Research & 2231 & 0.796 & 0.065 & 0.99 & 8 & 3.32 & 0.187 & 2 \\
J of Capital Univ of Econ and Business & 494 & 0.509 & 0.11 & 1 & 4 & 15.49 & 0.569 & 2 \\
Jiangsu Commercial Forum & 1295 & 0.31 & 0.056 & 0.97 & 5 & 5.95 & 0.442 & 1 \\
Logistics Sci-Tech & 1607 & 0.507 & 0.098 & 0.95 & 6 & 5.9 & 0.36 & 1 \\
Studies of Fin and Accounting in Educ & 554 & 0.891 & 0.202 & 0.98 & 5 & 3.9 & 0.583 & 1 \\
J of Xi'an Univ of Finance and Econ & 512 & 0.615 & 0.125 & 0.9 & 4 & 8.31 & 0.514 & 1 \\
J of Shijiazhuang University of Econ & 486 & 0.337 & 0.056 & 0.99 & 4 & 11.33 & 0.525 & 1 \\
\hline
\end{tabular}

Next, it adopts equalization method in dimensionless treatment to the data in Table 1. The processing results (portion) shown in Table 2.

Table 2. The processing results (portion) in equalization method to the data of evaluation indicators

\begin{tabular}{llllllll}
\hline Journal Name & $a_{1}$ & $a_{2}$ & $a_{3}$ & $a_{4}$ & $a_{5}$ & $a_{6}$ & $a_{7}$ \\
\hline Econ Theory and Business Management & 1.0596 & 1.7034 & 1.8914 & 1.0323 & 1.3333 & 1.4948 & 1.3031 \\
Studies of International Fin & 1.1388 & 2.0635 & 1.9731 & 1.001 & 1.4815 & 1.1841 & 0.8253 \\
China Rural Survey & 0.8664 & 2.2302 & 1.8097 & 1.0115 & 1.4815 & 1.4501 & 1.4682 \\
J of Business Economics & 0.8317 & 1.0903 & 0.9982 & 1.0115 & 1.1852 & 1.8903 & 1.5081 \\
Economist & 1.1266 & 1.881 & 1.8622 & 1.0323 & 1.7778 & 1.0346 & 1.2058 \\
J of Shanghai Lixin Univ of Commerce & 0.1968 & 0.7867 & 0.9107 & 1.0323 & 0.5926 & 1.6174 & 1.6297 \\
Technology Economics & 0.8829 & 0.8085 & 1.4186 & 0.8863 & 0.8889 & 1.511 & 1.1989 \\
On Economic Problems & 1.1961 & 0.7758 & 1.0274 & 1.0115 & 1.037 & 0.542 & 0.8514 \\
Rural Economy & 1.4995 & 0.9891 & 0.7939 & 1.0115 & 1.037 & 0.5204 & 1.2214 \\
\hline
\end{tabular}

Then it discretizes the data of evaluation indicators in Table 2 by equidistance division method. As the journals selected have 4 grades, the range between the minimum and maximum is divided into 4 intervals. The integers from 1 to 4 are assigned to 4 intervals from small to large. The discrete results (portion) shown in Table 3 . 
Table 3. The discrete result (portion) of evaluation indicators

\begin{tabular}{|c|c|c|c|c|c|c|c|c|}
\hline Journal Name & $a_{1}$ & $a_{2}$ & $a_{3}$ & $a_{4}$ & $a_{5}$ & $a_{6}$ & $a_{7}$ & $\mathrm{~d}$ \\
\hline Economic Theory and Business Management & 1 & 3 & 4 & 4 & 3 & 3 & 4 & 4 \\
\hline Studies of International Finance & 1 & 4 & 4 & 3 & 3 & 2 & 2 & 4 \\
\hline China Rural Survey & 1 & 4 & 4 & 4 & 3 & 3 & 4 & 4 \\
\hline Journal of Business Economics & 1 & 2 & 2 & 4 & 3 & 3 & 4 & 4 \\
\hline Economist & 1 & 4 & 4 & 4 & 4 & 2 & 3 & 4 \\
\hline Journal of Shanghai Lixin University of Commerce & 1 & 2 & 2 & 4 & 1 & 3 & 4 & 3 \\
\hline Technology Economics & 1 & 2 & 3 & 1 & 1 & 3 & 3 & 3 \\
\hline On Economic Problems & 1 & 2 & 2 & 4 & 2 & 1 & 2 & 3 \\
\hline Rural Economy & 1 & 2 & 2 & 4 & 2 & 1 & 3 & 3 \\
\hline
\end{tabular}

Impact factor, cited rate, $\mathrm{H}$ index, ratio of funded papers is selected as key evaluation indicators through reduction algorithm of Rough Set. Li et al. (2007) calculated the weighted value of each evaluation indicators with the mathematical integration method and selected current-year index, impact factor and ratio of funded papers as key indicators. The key evaluation indicators selected above include impact factor and ratio of funded papers, and $\mathrm{H}$ index and cited rate are considered seriously in many journal evaluation systems. So the key indicators selected through reduction algorithm of Rough Set are reasonable.

\subsection{Weights Determination of Key Evaluation Indicators}

\subsubsection{Weights Determination of Key Evaluation Indicators Based on Grey Correlation Method}

The data (portion) of 4 key indicators selected through reduction algorithm of Rough Set shown in Table 4. The weights of indicators are calculated by gray correlation advantage analysis.

Table 4. The data (portion) of 4 key evaluation indicators

\begin{tabular}{llllll}
\hline Journal Name & $a_{2}$ & $a_{4}$ & $a_{5}$ & $a_{7}$ & $\mathrm{~d}$ \\
\hline Economic Theory and Business Management & 1.717 & 0.99 & 9 & 0.75 & 4 \\
Studies of International Finance & 2.08 & 0.96 & 10 & 0.475 & 4 \\
China Rural Survey & 2.248 & 0.97 & 10 & 0.845 & 4 \\
Journal of Business Economics & 1.099 & 0.97 & 8 & 0.868 & 4 \\
Economist & 1.896 & 0.99 & 12 & 0.694 & 4 \\
J of Shanghai Lixin University of Commerce & 0.793 & 0.99 & 4 & 0.938 & 3 \\
Technology Economics & 0.815 & 0.85 & 6 & 0.69 & 3 \\
On Economic Problems & 0.782 & 0.97 & 7 & 0.49 & 3 \\
Rural Economy & 0.997 & 0.97 & 7 & 0.703 & 3 \\
\hline
\end{tabular}

First, it calculates the initial images of each sequence. Let

$$
A_{i}^{\prime}=A_{i} / a_{i}(1)=\left(a_{i}^{\prime}(1), a_{i}^{\prime}(2), \cdots, a_{i}^{\prime}(5)\right), i=0,1,2, \cdots, 20
$$

And the initial images of each sequence shown in Table 5.

Table 5. The initial images of each sequence

\begin{tabular}{ccccc}
\hline$a_{2}$ & $a_{4}$ & $a_{5}$ & $a_{7}$ & $\mathrm{~d}$ \\
\hline 1 & 1 & 1 & 1 & 1 \\
1.2114 & 0.9697 & 1.1111 & 0.6333 & 1 \\
1.3093 & 0.9798 & 1.1111 & 1.1267 & 1 \\
0.6401 & 0.9798 & 0.8889 & 1.1573 & 1 \\
1.1043 & 1 & 1.3333 & 0.9253 & 1 \\
0.4619 & 1 & 0.4444 & 1.2507 & 0.75 \\
0.4747 & 0.8586 & 0.6667 & 0.92 & 0.75 \\
0.4554 & 0.9798 & 0.7778 & 0.6533 & 0.75 \\
0.5807 & 0.9798 & 0.7778 & 0.9373 & 0.75 \\
1.0163 & 0.8889 & 1 & 1.076 & 0.75 \\
0.1706 & 0.9899 & 0.8889 & 0.124 & 0.5 \\
0.537 & 0.9394 & 0.5556 & 0.8707 & 0.5 \\
\hline
\end{tabular}




\begin{tabular}{ccccc}
\hline 0.4706 & 0.9596 & 0.4444 & 0.4333 & 0.5 \\
0.4636 & 1 & 0.8889 & 0.2493 & 0.5 \\
0.2964 & 1.0101 & 0.4444 & 0.7587 & 0.5 \\
0.1805 & 0.9798 & 0.5556 & 0.5893 & 0.25 \\
0.2953 & 0.9596 & 0.6667 & 0.48 & 0.25 \\
0.5189 & 0.9899 & 0.5556 & 0.7773 & 0.25 \\
0.3582 & 0.9091 & 0.4444 & 0.6853 & 0.25 \\
0.1963 & 1 & 0.4444 & 0.7 & 0.25 \\
\hline
\end{tabular}

Secondly, calculate the sequence of differences. Using formula

$$
\Delta_{i}(j)=\left|a_{i}^{\prime}(j)-a_{i}^{\prime}(5)\right|
$$

Where, $i=1,2, \cdots, 18, j=1,2, \cdots, 5$. The sequences of differences are shown in Table 6 .

Table 6. The sequences of differences

$\begin{array}{|lllll|}0.2114 & 0.0303 & 0.1111 & 0.3667 & 0 \\ 0.3093 & 0.0202 & 0.1111 & 0.1267 & 0 \\ 0.3599 & 0.0202 & 0.1111 & 0.1573 & 0 \\ 0.1043 & 0 & 0.3333 & 0.0747 & 0 \\ 0.2881 & 0.25 & 0.3056 & 0.5007 & 0 \\ 0.2753 & 0.1086 & 0.0833 & 0.17 & 0 \\ 0.2946 & 0.2298 & 0.0278 & 0.0967 & 0 \\ 0.1693 & 0.2298 & 0.0278 & 0.1873 & 0 \\ 0.2663 & 0.1389 & 0.25 & 0.326 & 0 \\ 0.3294 & 0.4899 & 0.3889 & 0.376 & 0 \\ 0.037 & 0.4394 & 0.0556 & 0.3707 & 0 \\ 0.0294 & 0.4596 & 0.0556 & 0.0667 & 0 \\ 0.0364 & 0.5 & 0.3889 & 0.2507 & 0 \\ 0.2036 & 0.5101 & 0.0556 & 0.2587 & 0 \\ 0.0695 & 0.7298 & 0.3056 & 0.3393 & 0 \\ 0.0453 & 0.7096 & 0.4167 & 0.23 & 0 \\ 0.2689 & 0.7399 & 0.3056 & 0.5273 & 0 \\ 0.1082 & 0.6591 & 0.1944 & 0.4353 & 0 \\ 0.0537 & 0.75 & 0.1944 & 0.45 & 0\end{array} \mid$

Thirdly, calculate the correlation coefficients,

$$
M=\max _{i} \max _{j} \Delta_{i}(j)=0.75, \quad m=\min _{i} \min _{j} \Delta_{i}(j)=0
$$

Let identification coefficient $\rho=0.5$, thus

$$
r_{i j}=\frac{m+\rho M}{\Delta_{i}(j)+\rho M}=\frac{0.375}{\Delta_{i}(j)+0.375}
$$

And the correlation coefficients showed in Table 7. 
Table 7. The gray correlation coefficient

$\begin{array}{|lllll|}a_{2} & a_{4} & a_{5} & a_{7} & \mathrm{~d} \\ 1 & 1 & 1 & 1 & 1 \\ 0.6395 & 0.9252 & 0.7714 & 0.5056 & 1 \\ 0.548 & 0.9489 & 0.7714 & 0.7475 & 1 \\ 0.5103 & 0.9489 & 0.7714 & 0.7044 & 1 \\ 0.7825 & 1 & 0.5294 & 0.834 & 1 \\ 0.5655 & 0.6 & 0.551 & 0.4282 & 1 \\ 0.5766 & 0.7755 & 0.8182 & 0.6881 & 1 \\ 0.5601 & 0.62 & 0.931 & 0.7951 & 1 \\ 0.6889 & 0.62 & 0.931 & 0.6669 & 1 \\ 0.5847 & 0.7297 & 0.6 & 0.535 & 1 \\ 0.5324 & 0.4336 & 0.4909 & 0.4993 & 1 \\ 0.9102 & 0.4605 & 0.871 & 0.5029 & 1 \\ 0.9273 & 0.4493 & 0.871 & 0.8491 & 1 \\ 0.9115 & 0.4286 & 0.4909 & 0.5994 & 1 \\ 0.6482 & 0.4237 & 0.871 & 0.5918 & 1 \\ 0.8437 & 0.3394 & 0.551 & 0.525 & 1 \\ 0.8923 & 0.3458 & 0.4737 & 0.6198 & 1 \\ 0.5824 & 0.3364 & 0.551 & 0.4156 & 1 \\ 0.7761 & 0.3626 & 0.6585 & 0.4628 & 1 \\ 0.8747 & 0.3333 & 0.6585 & 0.4545 & 1\end{array}$

Fourthly, calculate the grey correlation degrees. From

$$
r_{i}=\frac{1}{n} \sum_{i=1}^{n} r_{i j}=\frac{1}{20} \sum_{i=1}^{20} r_{i j}
$$

It gets the values of each grey correlation degree:

$r_{1}=0.7177, \quad r_{2}=0.6041, \quad r_{3}=0.7081, \quad r_{4}=0.6212$

Lastly, calculate the weights of each indicator:

$\omega_{1}=0.2707, \omega_{2}=0.2278, \omega_{3}=0.2671, \omega_{4}=0.2343$

\subsubsection{Weights Determination of Key Evaluation Indicators Based on Dominance-Based Rough Set}

Dominance-based rough set is another objective weight method. Here we use dominance-based rough set method, which was introduced in The Weight determination Based on Dominance-based Rough Set in Fuzzy Comprehensive Evaluation, to calculate another group of weights of 4 key indicators. The weights were obtained as follows:

$\omega_{1}^{\prime}=0.1154, \quad \omega_{2}^{\prime}=0.4846, \quad \omega_{3}^{\prime}=0.1538, \quad \omega_{4}^{\prime}=0.2462$

\subsection{The Comparative Results}

This paper selects 40 economics journals from A Report on Chinese Academic Journals Evaluation as research objects, as well as searches the data of seven common evaluation indicators of these journals from CHINESE S\&T JOURNAL REPORTS (Expanded Edition). Combined with the previous two groups of weights determined by grey correlation method and dominance-based rough set method, the TOPSIS method is used to calculate the comprehensive scores of the 40 economics journals selected and sort these journals according to their scores. Then it gets the ranking by TOPSIS based on grey correlation( $\mathrm{G}$ for short) and the ranking by TOPSIS based on dominance-based rough set(D for short).It also searches the ranking of these journals in A Report on Chinese Academic Journals Evaluation(R for short).Three rankings above shown in Table 8. Here we abbreviate a part of journals names because of space limitations. 
Table 8 . The rankings for journals

\begin{tabular}{|c|c|c|c|c|c|c|c|}
\hline Journal Name & $\mathrm{R}$ & $\mathrm{G}$ & $\mathrm{D}$ & Journal Name & $\mathrm{R}$ & $\mathrm{G}$ & $\mathrm{D}$ \\
\hline Economic Research Journal & 1 & 1 & 1 & Intergrade & 21 & 27 & 15 \\
\hline Accounting Research & 2 & 2 & 2 & Economic Survey & 22 & 23 & 30 \\
\hline China Industrial Economics & 3 & 3 & 3 & Contemporary Econ \& Management & 23 & 20 & 20 \\
\hline J of Financial Research & 4 & 5 & 5 & Taxation Research & 24 & 21 & 31 \\
\hline The Journal of World Economy & 5 & 4 & 4 & Reformation \& Strategy & 25 & 29 & 33 \\
\hline Journal of International Trade & 6 & 7 & 7 & Friends of Accounting & 26 & 30 & 24 \\
\hline Tourism Tribune & 7 & 8 & 6 & Economic Issues in China & 27 & 26 & 39 \\
\hline Chinese Rural Economy & 8 & 13 & 8 & Agricultural Economy & 28 & 32 & 25 \\
\hline Journal of Finance and Economics & 9 & 6 & 9 & Public Finance Research & 29 & 31 & 40 \\
\hline Finance \& Trade Economics & 10 & 10 & 13 & Asia-pacific Econ Review & 30 & 18 & 28 \\
\hline Contemporary Finance \& Economics & 11 & 9 & 10 & Economy and Management & 31 & 33 & 38 \\
\hline World Economy Study & 12 & 12 & 17 & Shanghai Finance & 32 & 39 & 29 \\
\hline Auditing Research & 13 & 11 & 12 & $\mathrm{~J}$ of Econ of Water Resources & 33 & 25 & 32 \\
\hline Modern Economic Science & 14 & 17 & 22 & The World of Survey and Research & 34 & 28 & 26 \\
\hline Inquiry into Economic Issues & 15 & 24 & 11 & South China Finance & 35 & 40 & 36 \\
\hline Economic Review & 16 & 14 & 14 & Chin Univ Technology Transfer & 36 & 38 & 21 \\
\hline Finance and Trade Research & 17 & 22 & 27 & Finance and Economy & 37 & 36 & 34 \\
\hline Securities Market Herald & 18 & 19 & 23 & Jiangsu Commercial Forum & 38 & 34 & 18 \\
\hline Macroeconomics & 19 & 16 & 19 & $\mathrm{~J}$ of Xi'an Univ of Fin and Econ & 39 & 37 & 37 \\
\hline On Economic Problems & 20 & 15 & 16 & Special Zone Economy & 40 & 35 & 35 \\
\hline
\end{tabular}

As seen in Table 8, the five top in G Ranking and D Ranking are the same and largely consistent with R Ranking. It is normal that three kinds of rankings above have differences because they use different evaluation methods. There is still a good agreement among them. Next, it compared G Ranking with D Ranking.

From the weights of comparison, it can be seen that in the weight determination based on dominance-based rough set, cited rate has a weight of 0.4846 , ratio of funded papers has a weight of 0.2462 , but the weights of $\mathrm{H}$ index and impact factor are only 0.1538 and 0.1154 . $\mathrm{H}$ index and impact factor are two important evaluation indicators in journal evaluation and generally $\mathrm{H}$ index is more important than ratio of funded papers. Thus the weight determination based on dominance-based rough set here is inappropriate. By contrast, the weights determined by grey correlation are more reasonable. Impact factor has a highest weight of 0.2707 and $\mathrm{H}$ index had a higher weight than ratio of funded papers.

As the ranking in A Report on Chinese Academic Journals Evaluation is more authoritative and has a high reference value, here we use the square error sum to measure the proximity of $G$ ranking to $R$ ranking and the proximity of $\mathrm{D}$ ranking to $\mathrm{R}$ ranking. From Table 8 it can calculate that the square error sum between $\mathrm{G}$ Ranking and R Ranking is 680 and the square error sum between D Ranking and R Ranking is 1556. Thus G Ranking is closer to R Ranking.

Above all, in evaluation of economics journals, the evaluation of economics journals model based on reduction algorithm of Rough Set and Grey Correlation can select rational key indicators and get rational weights of these indicators. And the evaluate result is reasonable. Thus this evaluation model has a certain reasonability and practicality.

\section{Conclusion}

This paper proposed an evaluation of economics journals model based on reduction algorithm of Rough Set and Grey Correlation to evaluate economics journals. It used rough set reduction method to select the key evaluation indicators, which simplified the evaluation system. Compared with the dominance-based rough set, grey correlation method allocated the indicators weights more reasonably and succinctly here. Lastly we combined the TOPSIS with the weights determined by grey correlation and dominance-based rough set to evaluate and rank economics journals. The results showed that the evaluation of economics journals model based on reduction algorithm of Rough Set and Grey Correlation has a certain reasonability and practicality. The evaluation of economics journals model based on reduction algorithm of Rough Set and Grey Correlation has general applicability. Here we only apply this model in the evaluation of economics journals, it is practical to adjust this model to be applied in other field. Besides, Rough set, grey correlation and TOPSIS are commonly used in academic evaluation field.

The selection and weight for evaluation indicators and the evaluation rules in comprehensive evaluation system 
have important influence on valuation result of the system. It is better to consider the reasonability of different components to establish scientific and objective evaluation system. The integration of these methods can be applied in other fields such as the environmental quality assessment (Wang et al., 2014), short-term wind speed forecasting (Yin et al., 2014) and so on.

\section{Acknowledgements}

The project of the college students' innovation and entrepreneurship training plan in Jinan university (national level) (No. 201410559004).

\section{References}

Deng, J. L. (2002). Grey prediction and grey decision-making. China, Wuhang: Huazhong University of Science and Technology Press.

Li, Z. Q., Liu, X., Liu, M, S., \& Wang, Y. B. (2007). Ascertainment and discussion on weighted value of academic quality evaluation indexes of journals. Acta Editologica, (19), 389-390.

Liu, M, S., Zhou, X. M., Dai, G. J., Tong, J. G., \& Li, Z. Q. (2006). Analysis of relationship between academic index using normalization method and conventional evaluation results for sci-tech periodicals. Acta Editologica, (6), 468-471.

Lv, Y. J., Zhang, X. N., \& Wei, B. P. (2012). The Weight detemination Based on Dominance-based Rough Set in Fuzzy Comprehensive Evaluation. Statistics and Decision, (20), 44-46.

Pawlak, Z. (1982). Rough set. International Journal of Computer and Information Sciences, (11), 341-356.

Qian, W. Y., Dang, Y. G., Xiong, P. P., \& Wang, Z. X. (2008). Topsis Based on Grey Correlation Method and Its Application. Systems Engineering, (27), 124-126.

Wang, L. L., Lu, X. N., \& Sun, Z. G. (2014). Application of Improved Topsis in Atmospheric Environmental Quality Assessment. Environmental Engineering, (9), 142-146. http://dx.doi.org/ 10.13205/j.hjgc.201409032

Wang, L. Z., \& Yu, L. P. (2012). Study on Key Indicators Definition and Its Impact in the Evaluation Academic Journals. New Technology of Library and Information Service, (7), 103-108.

Xiao, J. H., \& Wu, J. P. (2001). The Evaluation Method for Science Research Project based on Rough Set. Science Research Management, (9), 8-12.

Xiong, P., Cheng, H. B., \& Wu, X. P. (2003). A synthetic weighting method based on rough sets. Journal of Naval University of Engineering, (15), 53-56.

Yin, D. Y., Sheng, Y. F., Jiang, M. J., Li, Y. S., \& Xie, Q. T. (2014). Short-term wind speed forecasting using Elman neural network based on rough set theory and principal components analysis. Power System Protection and Control, (11), 46-51.

Zhang, H., Zhao, H. X., Liu, Y. P., \& Tao, W. W. (2008). Evaluation method on sci-tech journals based principle component analysis. Acta Editologica, (1), 87-90.

Zhou, C. D. (2008). On Attribute Reduction Based on Rough Set Theory (Master's thesis). Hefei: Hefei University of Technology, Hefei, China.

\section{Copyrights}

Copyright for this article is retained by the author(s), with first publication rights granted to the journal.

This is an open-access article distributed under the terms and conditions of the Creative Commons Attribution license (http://creativecommons.org/licenses/by/3.0/). 